\title{
HERMENÊUTICA CONSTITUCIONAL NO PARADIGMA DA DIFFÉRENCE
}

\author{
CONSTITUTIONAL HERMENEUTICS IN THE PARADIGM OF DIFFÉRENCE
}

Rafael Lazzarotto Simioni ${ }^{1}$

Resumo: Nesta pesquisa objetivou-se estabelecer uma reflexão crítica sobre o problema do compromisso da interpretação constitucional do STF com os referentes tradicionais do direito. Partindo de uma releitura do problema kelseniano da indeterminação da linguagem, queremos apresentar à discussão o problema do referente, isto é, o problema da escolha discricionária não apenas da relação semiológica entre significado e significante, que é o problema do decisionismo judicial, mas o problema da escolha arbitrária do sistema simbólico que constitui o referente interpretativo da decisão jurídica em cada caso. Nossa hipótese é a de que a prática da interpretação constitucional do STF se caracteriza por um externalismo semântico típico do paradigma da Différence. Para serem alcançados esses resultados, utiliza-se como metodologia os aportes teóricos do novo realismo especulativo de Quentin Meillassoux, de modo a explicitar o correlacionismo presente na hermenêutica constitucional brasileira e apresentar uma nova perspectiva de discussão sobre o problema do referente jurídico. Como resultado, conclui-se que o problema da hermenêutica constitucional pode ser compreendido não apenas como um problema de indeterminação da linguagem "aberta" dos princípios constitucionais, tampouco como um problema de interpretação subjetivista do juiz, mas também como um problema inscrito nas relações de poder entre as instituições jurídicas (judiciário, advocacia pública, advocacia privada e academia) pela ocupação dos espaços de produção de sentido do direito.

Palavras-chave: Hermenêutica constitucional. Interpretação jurídica. Correlacionismo. Pluralismo jurídico. Différence.
Abstract: This research aimed to establish a critical reflection about the problem of the commitment of the constitutional interpretation by the STF (Brazilian Supreme Court) with the traditional referents of the Law. Starting from a rereading of the Kelsenian problem of the indeterminacy of language, we want to present the problem of the referent to the discussion, that is, the problem of the discretionary choice not only of the semiological relation between meaning and significant, which is the problem of judicial decisionism, but the problem of the arbitrary choice of the symbolic system that constitutes the interpretative reference of the judicial decision in each case. Our hypothesis is that the manner of constitutional interpretation by STF is characterized by a semantic externalism typical of the Differrence paradigm. In order to achieve these results, will be used as methodology the theoretical contributions of the new speculative realism by Quentin Meillassoux, in order to make explicit the co-relationism present in the Brazilian constitutional hermeneutics and present a new perspective of discussion on the problem of the legal referent. As a result, we find that the problem of constitutional hermeneutics can be understood not only as a problem of indetermination by "open" language of constitutional principles, either as a problem of subjectivist interpretation by judges, but also as a problem inscribed in the power relations between legal institutions (judiciary, public defender, private advocacy and academy) for the occupation of the spaces of production of law meaning.

Keywords: Constitutional hermeneutics. Constitutional Court. Co-relationism. Juridical pluralism. Différence.

\footnotetext{
1 Pós-Doutor em Teoria e Filosofia do Direito pela Universidade de Coimbra; Doutor em Direito Público pela Universidade do Vale dos Sinos; Professor no Programa de Mestrado em Direito da Faculdade de Direito do Sul de Minas e no Programa de Mestrado em Bioética da Universidade do Vale do Sapucaí; Avenida Prefeito Tuany Toledo, 470, Fátima, 37550-000, Pouso Alegre, Minas Gerais; simioni@ufmg.br
} 


\section{Introdução}

A hermenêutica constitucional dominante no Brasil tem entendido o problema da interpretação das normas constitucionais como uma questão de incompletude do sistema simbólico que constitui o referente interpretativo dos tribunais. Esse modo de entender a problemática da interpretação constitucional afirma que o problema está na maior abertura e grau de abstração da linguagem dos princípios constitucionais, que permitem ao intérprete um amplo espaço de discricionariedade. Assim, nessa perspectiva, a tarefa da hermenêutica constitucional seria a de limitar ou controlar o processo de atribuição de sentido, que um intérprete faz, a respeito das normas constitucionais.

Entretanto, essa perspectiva teórica de compreensão do problema hermenêutico constitucional, produzida por importantes ministros do STF em suas doutrinas e reproduzida de modo hegemônico nos cursos e concursos jurídicos do Brasil, é uma perspectiva que não dá um passo sequer além daquilo que Kelsen já questionava acerca do problema da insuperável indeterminação da linguagem do direito. Um problema, aliás, que acontece não apenas no nível da suposta abertura principiológica da constituição, mas em todo o sistema de normas jurídicas, em todos os níveis e dimensões do ordenamento jurídico. A moldura da discricionariedade interpretativa do direito é um problema presente em todos os níveis do processo de construção interpretativa do sentido do direito e não apenas um desafio para a elite dos intérpretes da constituição brasileira.

Um olhar diferente sobre a problemática da interpretação constitucional pode ser encontrada na hermenêutica constitucional crítica, especialmente sob a matriz filosófica (STRECK, 2001, 2002, 2006). A hermenêutica crítica procurou questionar esse modo positivista de se entender a problemática da interpretação constitucional e evidenciou o problema do solipsismo judicial e da falta de compromisso do intérprete com a coerência e com a consistência das decisões jurídicas, permitindo entender melhor os fenômenos do decisionismo judicial, da judicialização da política, do ativismo judicial e da mutação constitucional em nossa realidade. A hermenêutica jurídica crítica tem procurado denunciar o subjetivismo, o arbítrio e a incoerência da prática interpretativa brasileira com o horizonte autêntico de sentido constituído pela referência aos direitos fundamentais sociais. Outra linha importante de pesquisas críticas parte da análise empírica dos esquemas de fundamentação das decisões judiciais no Brasil, para observar a existência de "zonas de autarquia" (RODRIGUEZ, 2017, p. 58) baseadas na combinação de argumentos de autoridade com opiniões pessoais dos julgadores.

Nessa pesquisa, todavia, encetaremos um caminho diferente. Não melhor, tampouco pior, apenas diferente: pretendemos colocar à discussão o problema da interpretação constitucional do STF como um problema inscrito em uma temporalidade típica do paradigma da Différence. Chamamos de paradigma da Différence o pensamento pós-crítico da geração de 1968: Foucault, Derrida, Guattari, Klossowski, Deleuze, Blanchot e outros. Um paradigma correlacionista que apresenta seus sinais de triunfo em vários domínios do conhecimento: na educação, sexualidade, administração, religião, ciência, política, ética e no direito. 
Nossa hipótese é a de que, embora o STF se auto-afirme neopositivista, procedimentalista ou neoconstitucionalista e embora o STF convoque conceitos de Alexy, Dworkin, Habermas, Häberle e outros, seu modus operandi não é uma simples referência kelseniana à legitimidade pela competência estatal, ao argumento de autoridade e à opinião pessoal de cada julgador. $\bigcirc$ modus operandi do STF é mais complexo do que isso.

Uma pesquisa hermenêutica sobre a realidade da prática interpretativa dos tribunais brasileiros pode prescindir de um "modelo de racionalidade" suposto como válido. Especialmente porque, segundo nossa hipótese, a questão da interpretação constitucional do STF apresenta um caráter incompatível com a pretensão de coerência, de unidade e de convergência dos modelos teóricos. Pelo contrário, o modus operandi do STF a presenta algumas características típicas do pensamento desconstrucionista da Différence: plurirreferencialidade, incoerência, assimetria, dispersão, ausência de compromisso absoluto com as fontes tradicionais do direito, abertura argumentativa para referências de sentido exteriores ao direito, como os motivos econômicos, políticos, morais, científicos, etc. E isso é importante para se entender o que está acontecendo na realidade do direito brasileiro.

No que segue, esta pesquisa objetiva estabelecer uma reflexão sobre o problema do compromisso da interpretação constitucional do STF com os referentes tradicionais do direito no paradigma da Différence. Partindo de uma releitura do problema kelseniano da indeterminação da linguagem na interpretação constitucional, queremos apresentar à discussão o problema do referente, isto é, o problema da escolha discricionária não apenas da relação semiológica entre significado e significante, que é o problema do decisionismo judicial, mas sobretudo o problema da escolha arbitrária do sistema simbólico que constitui o referente interpretativo da decisão jurídica em cada caso.

Por hipótese, sinalizamos a adoção de um modelo plurirreferencial de interpretação jurídica pelo STF e possivelmente pelos demais tribunais superiores. Um modelo de interpretação baseado em um externalismo semântico radical, segundo o qual a determinação do sentido do direito não se encontra mais nos referentes tradicionais da interpretação jurídica, como foram as fontes do direito, mas, sim, em elementos exteriores e contingentes. Sinalizamos, também, por hipótese, que esse modelo de interpretação está ligado a um problema paradigmático que transcende à experiência jurídica: o paradigma da Différence, isto é, o triunfo de um sistema de pensamento que acredita não ser mais possível justificar a existência ontológica de um referente absoluto, necessário e cujo estatuto ontológico independa da correlação entre sujeito/objeto, percepção/consciência, noema/noemático, linguagem/mundo e distinção/referente.

Para serem alcançados esses resultados, utilizaremos como metodologia os aportes teóricos do novo realismo, especialmente na versão especulativa de Quentin Meillassoux (2006), de modo a explicitar o externalismo semântico radical presente na hermenêutica constitucional brasileira e apresentar uma nova perspectiva de discussão sobre o problema do referente jurídico. O pensamento da $D i$ fférence valoriza a polêmica, o dissenso, a dispersão, a assimetria, a divergência e a identidade incoerente (CEVOLO, 2016b, p. 569). Sob esse paradigma, a plurirreferencialidade na prática interpretativa dos 
tribunais superiores brasileiros, que temos assistido nos últimos anos, transforma o problema kelseniano da indeterminação da linguagem constitucional em um mero eufemismo do real.

\section{0 problema da hermenêutica constitucional}

Hans Kelsen (1985, p. 3) nos legou uma importante e influente contribuição: a noção de que o direito deve ser concebido como norma e não como texto legal, tampouco como costumes, interesses ou outras referências linguísticas da modernidade. Conceber o direito como norma significa, em Kelsen, entendê-lo como o resultado de uma interpretação construtiva da linguagem do direito, a partir da ideia de um ordenamento jurídico hierarquicamente e temporalmente organizado.

Sob essa forma linguística de organização das categorias de conhecimento do direito, a interpretação jurídica infraconstitucional deve ser realizada "à luz" das normas constitucionais, em um processo de construção do direito que parte da norma constitucional, passando pelas leis ordinárias, até culminar no direito específico para o caso concreto, realizado tanto pelas sentenças quanto pelos contratos (KELSEN, 1985, p. 247). Uma sentença, nessa perspectiva, segue o mesmo processo lógico-linguístico de construção do direito da legislação. Do mesmo modo que o legislador interpreta a Constituição para criar novas leis infraconstitucionais, também os juízes interpretam a Constituição e o ordenamento jurídico como um todo para criar as normas jurídicas individuais. A interpretação jurídica, para Kelsen, é um processo construtivo do direito.

O problema surge quando os juristas começam a se perguntar sobre a referência de sentido da própria Constituição. Afinal, para a interpretação da legislação infraconstitucional temos o horizonte hermenêutico da Constituição, mas para a interpretação da própria Constituição temos o quê?

A resposta de Kelsen foi uma proposição lógica e formal: a norma fundamental (KELSEN, 1985, p. 135, 1986, p. 328, 2000, p. 168). Uma norma hipotética, pressuposta, sem conteúdo, sem valor material, sem substância. Uma norma puramente conceitual, cuja função precípua é satisfazer o problema da consistência lógica de uma ordem jurídica concebida em termos de conjunto ou de sistema simbólico de um tipo especial. Veja-se que Kelsen poderia ter caído na tentação de apresentar, como fundamento das constituições, a política, a democracia, a assembleia constituinte ou outras fundamentações tradicionais do direito, como a moral, ética, justiça, razão, interesses, etc. Mas fiel aos preceitos do neopositivismo lógico do Círculo de Viena, Kelsen recorreu a uma estratégia teórica semelhante a de Bertrand Russel a respeito do paradoxo do conjunto que contém todos os conjuntos: um conjunto fundamental hipotético, que não possui estatuto ontológico, pois sua existência é puramente lógica, puramente conceitual, puramente hipotética (KELSEN, 1986, p. 329).

A estratégia teórica de Kelsen garantiu a coerência da sua teoria com o ideal de pureza. Mas despertou uma série de problemas: se a norma fundamental não possui conteúdo, não possui sequer forma, quais são os parâmetros supra ou transconstitucionais que os profissionais do direito devem utilizar para interpretar corretamente a Constituição? No nível da interpretação da legislação infra- 
constitucional esse problema não existe, porque essa legislação encontra, no nível da Constituição, o sistema simbólico que complementa suas arestas interpretativas. Mas no nível da interpretação constitucional, o problema da incompletude de um sistema simbólico (GÖDEL, 1992, p. 38; NAGEL; NEWMAN, 2003, p. 74) aparece: os profissionais do direito precisam buscar uma referência externa ao sistema simbólico de referência para encontrar um fundamento de consistência.

O problema da hermenêutica constitucional, no fundo, é o problema da incompletude de um sistema de referência: já que não há, em termos de um sistema de direito positivo, nada além da Constituição, qual é o sistema de referência correto para uma prática interpretativa da própria Constituição?

Os direitos humanos e o resgate neoconstitucionalista da noção de princípio desempenhou um papel fundamental nesse jogo simbólico de completar a incompletude sintática das normas constitucionais. A referência aos direitos humanos e, junto com ela, a noção simbólica de uma hierarquia constitucional dos direitos fundamentais positivados como cláusulas pétreas permitiu traçar uma diferença entre dois sistemas simbólicos no mesmo nível constitucional: os princípios fundamentais e as demais normas constitucionais. Desse modo, os princípios de direitos fundamentais puderam servir de referência constitucional, mas uma referência paradoxalmente aberta para valores, conteúdos, fundamentos e objetivos externos à própria constituição e ao ordenamento jurídico positivo como um todo. Isso porque os princípios fundamentais permitem conectar os limites lógico-sintáticos da sua linguagem normativa com a abertura semântica das problemáticas da política, economia, moral, ética, ecologia, etc. Quer dizer, os princípios fundamentais, segundo a leitura neoconstitucionalista, permitiram estabelecer um sistema de referência jurídico supra e transpostivista, no sentido de permitir a construção de parâmetros interpretativos da própria Constituição.

Dessa forma, do mesmo modo que Kelsen indicou a possibilidade do recurso à leitura constitucional das normas jurídicas infraconstitucionais, como estratégia de fundamentação da consistência interpretativa do ordenamento jurídico, o neoconstitucionalismo permitiu traçar uma distinção hierárquica entre normas constitucionais que são princípios fundamentais e normas que não são esses princípios, de modo a possibilitar uma leitura constitucional adequada ao horizonte interpretativo dos direitos fundamentais como direitos humanos positivados.

O problema é que, tanto no Brasil quanto em outras experiências jurídicas do mundo ocidental, os direitos fundamentais também são normas, quer dizer, também são o resultado de interpretações construtivas de uma ordem jurídica, igualmente submetidas ao problema da incompletude dos sistemas simbólicos em geral. O paradoxo está no fato, portanto, de os direitos fundamentais "fecharem" o argumento da consistência de uma determinada interpretação, justamente mediante a "abertura" argumentativa propiciada pelo sentido transpositivo dos direitos humanos. Em outras palavras, a referência aos princípios fundamentais é uma forma de justificação da consistência de uma interpretação jurídica, que só funciona porque os princípios fundamentais permitem uma abertura argumentativa da clausura sintática do ordenamento jurídico. A argumentação baseada em 
princípios, então, abre o sistema justamente para fechá-lo. E isso significa a persistência do problema da incompletude de Gödel (1992, p. 38), agora transferida para o nível dos princípios: qual é o sistema simbólico de referência que podemos utilizar para completar a incompletude dos princípios? Qual é o horizonte interpretativo dos princípios fundamentais, como dignidade, liberdade, igualdade, saúde, educação e vida?

\section{Hermenêutica constitucional e plurirreferencialidade}

Uma rápida olhada nos precedentes judiciais, nas peças processuais e na doutrina jurídica reproduzida nos meios acadêmicos do direito no Brasil, especialmente no nível da graduação, permite constatar facilmente que a referência à dignidade, à liberdade, à igualdade e aos demais direitos fundamentais sociais constitui o argumento que fecha o argumento, isto é, a abertura argumentativa que, paradoxalmente, fecha o argumento. Os problemas interpretativos são resolvidos e justificados, no fim das contas, com base na dignidade ou em outro direito fundamental social convocado para "fechar" o argumento. Mas justamente os conceitos de dignidade, liberdade, igualdade ou outro direito social não são colocados em questão. Precisamente porque questionar o significado do signo "dignidade" consiste em demonstrar tanto a contingência da relação entre significante e significado, quanto a persistência da incompletude do sistema de referência (DERRIDA, 1972, p. 6).

Referências ao significado de dignidade e outros direitos fundamentais sociais só funcionam como "fechamento" argumentativo de uma proposta de interpretação enquanto eles não são definidos - e por isso são apresentados como suposições metafísicas, místicas, fideístas, superiores (e transimbólicas) de racionalidade ou de justificação. Se o intérprete conhece a diferença entre a dignidade na Ética a Nicômaco de Aristóteles, a dignidade como diferença de valor e preço na Fundamentação da Metafísica dos Costumes de Kant ou a dignidade como dimensão política em Hannah Arendt ou, ainda, dignidade como emancipação em Habermas, por exemplo, a referência à dignidade já se torna questionável e contingente, e o uso dela como referência interpretativa já não "fecha" mais o argumento. $\bigcirc$ fantasma de Gödel reaparece: o sistema de referência utilizado para completar a incompletude do sistema constitucional também é, por sua vez, incompleto. O sistema de referência convocado para fundamentar a consistência da interpretação constitucional também precisa de fundamento.

Kelsen conhecia esse problema. Não apenas porque Gödel também fez parte do Círculo de Viena, mas porque ele dedicou as últimas páginas do seu Teoria Pura do Direito para oferecer um critério de completude da referência interpretativa do direito: a competência. Traçando uma distinção entre interpretação autêntica e interpretação inautêntica, Kelsen (1985, p. 245) propõe que, apesar da indeterminação linguística do direito e da inevitável margem de discricionariedade da interpretação (a "moldura" interpretativa do direito), existem normas que atribuem a competência para a criação de direito com caráter vinculante. Assim, a interpretação construtiva do direito, realizada por um juiz competente, possui poder de vinculação dos destinatários. Não porque é uma interpretação 
correta, justa ou adequada a princípios, valores ou outras referências externas ao direito, mas porque é uma interpretação realizada por um órgão que possui competência para produzir interpretações vinculantes (KELSEN, 1985, p. 249). A doutrina jurídica, a petição de um advogado ou o parecer do Ministério Público podem ser interpretações eruditas e esclarecidas de uma norma jurídica. Mas essas interpretações, para Kelsen, não possuem poder de vinculação e, por isso, são apenas propostas de interpretação que não vinculam os destinatários - são interpretações inautênticas.

$\mathrm{Na}$ teoria pura do direito de Kelsen é a competência que define a correção de uma interpretação jurídica. E isso nada mais é do que uma versão eufemística do que está acontecendo hoje na prática jurídica brasileira.

\section{Hermenêutica constitucional e o problema do decisionismo judicial}

Decisionismo judicial: já que a correção do direito está na competência e não no compromisso com a realização dos direitos fundamentais sociais - ou com a consciência de uma teoria política consistente de fundo -, então a interpretação jurídica pode convocar, ao seu bel prazer, a referência de sentido que lhe convier para a construção de sentido do direito em cada caso. O problema da hermenêutica constitucional, hoje, não é mais como interpretar corretamente as normas constitucionais à luz dos direitos fundamentais. O problema é como justificar a seleção de uma referência simbólica contingente para justificar uma determinada interpretação constitucional.

No neoconstitucionalismo estávamos preocupados com o respeito aos limites semânticos das normas constitucionais. Hoje estamos preocupados com o fato de o problema não ser os limites semânticos, mas a escolha arbitrária de uma referência simbólica contingente e, muitas vezes, guiada por uma teoria política de fundo para definir os próprios limites semânticos das normas constitucionais. O problema do decisionismo, na atualidade brasileira, tem a ver com uma prática jurídica que acredita poder transitar entre diversas e contingentes referências de sentido, ao lado da tradicional referência aos limites sintáticos dos textos legais.

Decisionismo judicial sempre existiu na história da cultura jurídica ocidental. Desde os pretores e censores romanos até os juízes modernos, as referências de sentido utilizadas na interpretação do direito são aleatórias, historicamente contingentes e escolhidas de modo subjetivista. Não subjetivista no sentido de um livre arbítrio na interpretação jurídica, mas no sentido da reprodução de um determinado conceito de direito ligado aos estratos sociais dominantes de cada época e de cada lugar. O recurso à "natureza das coisas" ou à "vontade de Deus" no jusnaturalismo ilustra isso. Como também a convocação da razão no jusracionalismo, o dogma da completude do texto do Code Civil no positivismo exegético do século XIX, o volksgeist no pandectismo alemão do século XIX, os interesses legítimos na Jurisprudência dos Interesses, dos bens, valores e, atualmente, os princípios na ponderação de Alexy são todas referências igualmente contingentes e, nesse sentido, subjetivistas, decisionistas. 
Até mesmo a escolha de uma teoria da interpretação jurídica e não outra é uma escolha decisionista. Especialmente porque hoje existem várias teorias igualmente importantes discutindo a questão da interpretação, da argumentação e da decisão jurídica. A afirmação de que, havendo colisão de princípios, há um dever de ponderação é arbitrária, genuinamente decisionista, porque a ponderação é apenas uma dentre várias outras importantes teorias da interpretação, da argumentação e da decisão jurídica.

A questão então é: por que e desde quando o decisionismo judicial se tornou um problema de interpretação jurídica? Por que e desde quando a hermenêutica constitucional viu no decisionismo judicial uma ameaça a um, dentre outros igualmente possíveis, horizontes autênticos da interpretação constitucional?

Importante lembrar, também, nessa discussão, o fato do Código Civil de 2003 ter sido apresentado e festejado nos anos 1990 como "o código dos juízes", no sentido de ser um código com normas abertas, com conceitos propositalmente indeterminados, justamente para possibilitar aos juízes adaptarem a interpretação das suas normas de modo mais adequado e dinâmico aos casos concretos. Um código repleto de normas gerais e princípios escritos de modo a permitir, justamente, a adequação dos conceitos do Código Civil à luz dos princípios constitucionais. Como se o fantasma de Gödel pudesse ser exorcizado da interpretação do novo Código Civil pela referência glorificante aos princípios constitucionais. O resultado disso foi o problema do decisionismo como um problema de arbítrio subjetivo, isto é, como um problema liberal de falta de compromisso do sujeito individual com os textos jurídicos.

Mas a advocacia também é, no geral, decisionista: ela desenha o caso e realiza o pedido que lhe convém, ou melhor, que melhor convém aos seus clientes, ao seu mercado. A academia também é, em parte, decisionista: os discursos acadêmicos sobre o direito reproduzem teorias, conceitos e métodos de modo arbitrário, subjetivo, sem estabelecer uma discussão sobre a filosofia política de fundo que está por trás da escolha desta e não outra teoria do direito. O Ministério Público, a Defensoria, as Procuradorias também são decisionistas quando escolhem atuar nesta e não em outra frente política de trabalho. ${ }^{2}$ Quando escolhem privilegiar uma atuação na área da educação e não na área ambiental; na área da saúde e não na área da segurança pública, etc. O decisionismo, assim entendido, é uma característica institucional das profissões jurídicas. Ele não está no subjetivismo do juiz, do advogado, do promotor ou do professor de direito: está nos desenhos institucionais do sistema de organização cujas regras comandam os padrões de racionalidade das decisões nele realizadas.

A questão, portanto, não é criticar a falta de compromisso deste ou daquele juiz com a letra da lei ou com o significado de um princípio constitucional preterido na interpretação de um problema concreto. A questão é entender como é possível uma prática jurídica que tolera isso. Como

\footnotetext{
2 Assis (2012, p. 158) observou, de modo inovador, a importância da judicialização das políticas públicas de educação quando o processo de formação da política pública é compreendido e respeitado não só pelo judiciário, mas também pelo Ministério Público, pelas advocacias, enfim, pelo "comunicador da norma."
} 
é possível pensar no problema do decisionismo judicial como um problema inscrito em uma temporalidade e em uma estrutura que permite isso.

Nos termos de uma possível leitura semiológica (SAUSSURE, 2006, p. 81), o decisionismo é um problema criado pelo positivismo jurídico na forma de uma falta de correspondência entre o significante da norma para o juiz e o significado dela para nós. O direito positivo confere apenas um signo, o qual não controla, por si só, a relação entre significado e significante. Essa relação entre o significado da norma e o significante dela no caso concreto se torna, então, uma relação de poder (WARAT; ROCHA, 1995, p. 101). E somente os juízes, em razão da competência, possuem o poder de produzir interpretações - conexões entre significante e significado - de modo vinculante. Uma compreensão não positivista do direito, portanto, deveria ver esse problema sob outras categorias de entendimento. Deveria ver esse problema do decisionismo não como uma falta de compromisso com aquilo que nós esperamos que deva ser "O Referente" exclusivo do direito, mas, sim, como uma disputa política pela ocupação dos espaços de produção de sentido do direito, isto é, como uma relação de poder entre quem detém a epistéme do direito e quem a ela se encontra submetido.

$\mathrm{Na}$ época em que os costumes eram o referente jurídico foi necessário criar um novo referente para completar a incompletude daquele: o espírito comunitário do povo. Quando o positivismo jurídico institucionalizou a lei escrita como o novo referente exclusivo do direito, logo precisamos inventar um novo referente compatível com o positivismo: as constituições (que já existiam, mas que somente no paradigma positivista passariam a ter o sentido de normas jurídicas). Quando as constituições se descobrem, também elas, incompletas como referentes interpretativos do direito, construímos a referência aos princípios como direitos fundamentais sociais. E quando essas referências últimas se descobrem, também elas, incompletas, construímos outras: democracia, república, direito internacional transconstitucional, constitucionalismo societário, institucionalização de redes e outras formas de pluralismo jurídico.

\section{Hermenêutica dos princípios constitucionais e pluralismo jurídico}

Entendemos por pluralismo jurídico a pluralidade de referentes interpretativos do direito. Não limitamos nosso conceito a uma relação crítica entre direito oficial do Estado e direito não oficial criado de modo autônomo às margens das esferas estatais, convivendo em um mesmo espaço geográfico e tempo político (SANTOS, 2002, p. 169). Esse conceito é importante para entender a emergência de ordens jurídicas com altos graus de legitimidade à margem do Estado, mas é um conceito ligado a uma relação correlacionista entre direito e Estado, que pressupõe o Estado. Hoje podemos prescindir da distinção entre Estado e sociedade civil para discutir isso. Como também podemos ir além da noção de pluralismo na interpretação constitucional como abertura hermenêutica para o povo (HÄBERLE, 1997, p. 12). 
Um conceito mais abstrato de pluralismo permite observar a pluralidade no referente interpretativo do direito. Um pluralismo de referências interpretativas que, de modo contingente, são convocadas para sustentar uma ou outra posição argumentativa a respeito do sentido de uma interpretação constitucional. Nessa perspectiva mais abstrata, não é o direito ou a constituição que é plural, tampouco os atores jurídicos que realizam as interpretações, mas, sim, os seus referentes interpretativos. O pluralismo como diferença da singularidade (DELEUZE, 1969, p. 125) é uma questão que pode ser identificada como um pluralismo de fontes e não de direitos como uma experiência do mundo prático. A unidade do direito permanece estruturada mesmo diante de uma programação ou de uma semântica pluralista (LUHMANN, 1995, p. 95). Claro que um direito plurirreferente se torna diferente de um direito monorreferencial também no nível da estrutura e não apenas no nível da sua semântica, das suas autodescrições. Mas não precisamos questionar a unidade do direito nesse momento.

Queremos observar que, sob uma perspectiva teórica conhecida como o novo realismo, especialmente em sua versão especulativa (MEILLASSOUX, 2006), o pluralismo jurídico e suas formas de expressão possuem correspondências em outras áreas do conhecimento, o que aponta para uma hipótese importante de pesquisa: a hermenêutica constitucional saiu do paradigma positivista do direito e está sob o comando de um novo paradigma, que queremos chamar de paradigma da Différence, o qual, no campo do direito, aparece sob o nome de pluralismo.

Os indícios de que não estamos mais no paradigma positivista do direito podem ser observados tanto na prática interpretativa do STF, quanto na da academia. No STF, pode-se observar que os referentes utilizados nos votos de cada ministro já não são mais os textos legais ou os textos constitucionais. Mas também não há um outro referente absoluto no lugar dos textos legais. Na realidade, os ministros convocam diversos referentes de modo aleatório e contingente, conforme o argumento que eles pretendem, individualmente, sustentar. Isso transforma a prática interpretativa do direito em uma prática plurirreferencialista, quer dizer, o referente interpretativo convocado na argumentação de cada voto individual já não é mais um referente singular, como foram as fontes do direito nos positivismos jurídicos ou os princípios no neoconstitucionalismo, mas um referente plural, contingente e, inclusive, arbitrário: ora se convocam precedentes do STF, ora se convocam as razões do voto dos outros ministros, ora se convocam as razões dos próprios votos anteriores, ora são convocados inclusive precedentes das cortes do EUA e outros países da Europa como símbolos de sucesso civilizacional. E para fechar o argumento de autoridade, complementa-se a argumentação com referências às exigências políticas, econômicas, morais e outros suplementos argumentativos contingentes, geralmente ligados ao futuro, aos prováveis efeitos colaterais de uma outra possibilidade de decisão. ${ }^{3}$

\footnotetext{
3 A comprovação dessa afirmação depende de uma pesquisa empírica específica que, todavia, não podemos realizar nesta oportunidade. Esperamos que o leitor entenda isso como uma proposição especulativa baseada na experiência de observação da prática interpretativa do direito pelo STF em seus acórdãos.
} 
A referência às normas constitucionais tornou-se supérflua, e isso, segundo nossa leitura, não é um problema de decisionismo judicial subjetivista deste o daquele juiz. Trata-se de uma questão inscrita na estrutura do direito, nos sistemas de organização do direito, nos desenhos institucionais dos tribunais, da advocacia, do Ministério Público e da academia. Um problema da organização, não dos sujeitos individuais. Também optamos por não conceber o problema do decisionismo como um problema ético de falta de compromisso com os limites semânticos dos textos constitucionais. Naturalmente, podemos observar e entender essa nova postura política do STF de um ponto de vista ético e sinalizar o dever de reestabelecermos um compromisso com a guarda da constituição e dos direitos fundamentais sociais e não dos interesses dos grupos sociais e partidos políticos dos ministros, mas preferimos, nesta pesquisa, observar isso como uma questão de poder. $O$ decisionismo está, em nossa perspectiva, na escolha contingente e arbitrária de um referente interpretativo do direito, dentre outros igualmente possíveis, comandada por relações de poder inscritas na estrutura do sistema de organização do STF e, possivelmente, dos demais tribunais superiores.

a) Uma consequência disso: os referentes interpretativos tradicionais do direito não possuem mais poder argumentativo. E os sinais desse novo regime de verdade são evidentes. Basta observar a performance argumentativa em geral dos advogados, públicos ou privados, nas sustentações orais do STF, pugnando pela aplicação da lei, dos princípios, da presunção de inocência, etc. Esse tipo de referência argumentativa clássica do direito parece não funcionar mais. Porque o importante no direito - e também em outras áreas do saber, como veremos adiante - não é mais um referente único e absoluto, mas, sim, a plurirreferencialidade. Não é mais a unidade coerente dos precedentes, mas a unidade da diferença, a promoção da diversidade. $O$ estilo de argumentação jurídica utilizado pelos advogados nos anos 1980 e 1990 não funciona mais nos dias de hoje. Os clientes são condenados ou absolvidos por outros motivos, por outras razões - por quaisquer outras razões -, e a presunção de inocência, a ausência de provas ou essas referências clássicas do Iluminismo jurídico do século XIX já não funcionam mais. O próprio conceito de prova sofreu profundas transformações nos últimos tempos. A noção de documento, hoje, só faz sentido no contexto de um discurso que o organiza (FOUCAULT, 1969, p. 13), que seleciona um sentido em detrimento de outros, que estrutura o sentido do documento não por ele mesmo, mas pela relação que ele estabelece com o mundo exterior.

Os advogados dizem que não há provas para a condenação porque os documentos não são suficientes para comprovar a culpa. Mas eles não perceberam que os documentos, no modelo da plurirreferencialidade da interpretação jurídica, não possuem um sentido em si mesmos. Os documentos não são mais representações ou materializações de sentido independentes da correlação com o mundo exterior. Os documentos, hoje, são espaços vazios, páginas desertas: os seus sentidos são determinados por correlações estabelecidas por referências exteriores a eles mesmos. "Sombras vazias" de uma indiferenciabilidade absoluta (CEVOLO, 2016, p. 415).

b) Outra consequência desse modelo plurirreferencialista de interpretação jurídica é a transformação da prática jurídica em uma prática política. Se a determinação do sentido dos docu- 
mentos depende de correlações externas construídas por um intérprete, sem nenhum compromisso com um referente interpretativo em especial, então qualquer interpretação se torna possível. E isso significa que a expectativa de um advogado de convencer o tribunal a respeito de uma tese se torna uma expectativa provavelmente frustrada. A abertura política da plurirreferencialidade permite a convocação de outras referências de sentido. Inclusive o argumento do poder político da instituição ou organização representada pelo advogado. A questão do convencimento sobre qual tese deve prevalecer se torna uma questão de poder. Nesse cenário, já não são mais as grandes causas que fazem os grandes advogados, mas os grandes advogados que transformam as causas em grandes causas. E são os grandes clientes que transformam os advogados em grandes advogados. Em um sistema de sentido plurirreferencialista prevalecem as relações de poder. E nesse jogo, os argumentos que funcionam não são mais os argumentos positivistas que insistem no compromisso lógico-formal com os limites sintáticos dos textos legais, tampouco os argumentos neoconstitucionalistas que insistem em um compromisso com a coerência a princípios fundamentais, muito menos os argumentos éticos, que insistem no compromisso deontológico com os valores de uma determinada cultura jurídica.

c) $\mathrm{O}$ argumento que funciona, hoje, é o argumento da pluralidade, da diversidade, da promoção da diferença e não da unidade. A liberdade religiosa, por exemplo, é importante hoje não porque é uma garantia constitucional, mas porque é uma garantia de promoção da diversidade religiosa. A dignidade humana é importante, hoje, não porque é um direito humano fundamental, mais porque é uma garantia de promoção da diversidade dos modos de vida, da cultura e das formas de convivência social. A liberdade, outrossim, é importante hoje não porque é uma das virtudes mais originárias do direito, mas porque é garantia de promoção da diversidade de pensamento, de expressão, de modos de vida, de ideias de vida boa, de pluralidade de identidades, de autodeterminação, enfim, uma liberdade de escolha a respeito da diversidade de possibilidades de vida boa. $\bigcirc$ argumento da coerência soa conservador em uma prática jurídica plurirreferencialista. Porque o mais importante, hoje, sob o paradigma da Différence, é a promoção da diferença e não da unidade, é a construção da identidade incoerente e não da coerência ou da congruência entre os modos de vida. $\bigcirc$ mais importante, hoje, são as diversas formas de expressão da pluralidade, da diferença.

Mas a plurirreferencialidade na construção interpretativa do direito não é uma exclusividade do modus operandi do STF e dos tribunais superiores. Nos discursos acadêmicos também se tornam visíveis os sinais dessa transformação paradigmática da Différence no pensamento jurídico brasileiro. Podemos observar esses sinais por meio de uma comparação entre os discursos acadêmicos da constitucionalização do direito infraconstitucional (no Brasil, anos 1980 e 1990 no geral), os discursos acadêmicos da nova referência a princípios no neoconstitucionalismo (no Brasil, anos 2000 no geral) e os discursos acadêmicos contemporâneos, desconstrucionistas da referência metafísica à leitura neoconstitucionalista dos princípios e que apontam para outras referências de sentido ligadas, de modo geral, às diversas formas de expressão do pluralismo jurídico. 
Se observarmos as conclusões dos trabalhos acadêmicos dos anos 1990, poderemos constatar que as questões giravam em torno de mais educação, mais cidadania, mais democracia, mais distribuição de renda, mais liberdade e menos desigualdade social. ${ }^{4}$ Era a época da constitucionalização do direito privado, do direito penal, do processo, enfim, constitucionalização do direito infraconstitucional. Uma época em que a referência à constituição servia como "A Referência" de completude do sistema infraconstitucional. Um trabalho acadêmico que concluísse algo fora desse tipo de referência dominante do discurso jurídico daquela época era avaliado como errado, inadequado ou supérfluo. Um dos efeitos de paradigma é constituir os critérios sobre os quais um discurso jurídico está em conformidade ou em desconformidade com o regime de verdade instituído pelo próprio paradigma.

Já nos anos 2000 se generaliza, no Brasil, o discurso acadêmico do neoconstitucionalismo. Os trabalhos acadêmicos dessa época não falam mais em educação, saúde, cultura, cidadania, democracia e outros referentes constitucionais como soluções à suas problemáticas. Falam em princípios fundamentais, isto é, falam de uma referência interpretativa do direito no sentido de construir formas de interpretação jurídica realizadoras dos princípios fundamentais. ${ }^{5}$ Construções interpretativas potencializadoras da realização prática dos direitos fundamentais. Especialmente o princípio da dignidade humana. O referente suplementar agora não é mais a constituição em um sentido positivista, mas os princípios constitucionais e, em especial, o princípio da dignidade humana como um horizonte (referente) platônico, ideal, perfeito e até certo ponto mítico da interpretação jurídica. Princípios como "conceitos-emblema" (BADIOU, 2010, p. 7). Isso porque ninguém pode ser contra a dignidade humana. Especialmente enquanto ela é utilizada apenas em abstrato, como um conceito idealizado e romantizado do humanismo renascentista do século XVI. A leitura neoconstitucionalista procurou suplementar, por meio do resgate de uma leitura humanista dos princípios fundamentais, a incompletude do sistema simbólico formado pelo ordenamento jurídico constitucional. E esse referente principiológico da interpretação constitucional funcionou, no geral, até hoje. Entretanto, ao menos nos discursos acadêmicos em nível de pós-graduação, em geral, ele começa a apresentar sinais de esgotamento.

Esse tipo de discurso neoconstitucionalista ainda pode ser verificado nos discursos acadêmicos atuais. Mas ele já está desatualizado e identificado como um tipo de discurso ligado à dogmática jurídica. O modelo de discurso, hoje, privilegia o pluralismo jurídico e suas diversas formas de expressão. ${ }^{6}$ A questão, hoje, não é mais o problema kelseniano da eficácia ou da efetividade dos direi-

\footnotetext{
4 A comprovação dessa proposição depende de uma pesquisa empírica específica que, todavia, não podemos realizar nesta oportunidade. Esperamos que o leitor entenda isso como uma proposição especulativa baseada na experiência de observação empírica dos títulos e conclusões dos trabalhos acadêmicos dessa época.

5 A validade dessa proposição também depende de uma pesquisa empírica específica que, todavia, não podemos realizar nesta oportunidade. Esperamos que o leitor entenda isso como uma proposição especulativa baseada na experiência de observação empírica dos títulos e as conclusões dos trabalhos acadêmicos dessa época.

6 Uma fonte interessante de pesquisa empírica para comprovar essa proposição é o Prêmio Capes de Teses, que permite sinalizar essa transformação recente nos títulos, problemáticas, abordagens e conclusões dos trabalhos acadêmicos premiados. Com início em 2006, desde as edições de 2010 do Prêmio Capes de Teses, os trabalhos premiados na área jurídica giram em torno de conceitos ligados ao pluralismo jurídico e suas formas de expressão.
} 
tos fundamentais sociais, tampouco o problema neoconstitucionalista da interpretação realizadora do mínimo existencial dos princípios fundamentais sociais, mas, sim, o problema da diversidade de fontes, de perspectivas, de organizações, de instituições, de estruturas sociais, de modos de vida, de culturas, de soberanias, de sistemas constitucionais, de sistemas judiciários, de sistemas tributários, de meios de comunicação, enfim, problemas de pluralismo jurídico.

Sob o paradigma da Différence, o referente último do direito - que sempre é um penúltimo referente de sentido - desloca-se exatamente para aquilo que mais se coaduna com os preceitos desconstrucionistas do pensamento da Différence, que, segundo nossa leitura, não é mais a Constituição como norma hierarquicamente superior (neopositivismo jurídico), tampouco os princípios fundamentais como referências interpretativas das normas constitucionais (neoconstitucionalismo), mas, sim, o pluralismo jurídico e suas diversas formas de expressão (redes, organizações, descentralização, diversidade, complexidade, contingência, trans, inter, multi, eco, pós, etc.).

Embora em suas doutrinas e demais discursos os ministros do STF em geral possam se declarar positivistas, neoconstitucionalistas, procedimentalistas, substancialistas, pragmatistas ou qualquer outra concepção teórica de interpretação, argumentação e decisão jurídica, o modus operandi deles não é nenhum desses. É a Différence. A argumentação até pode convocar os recursos conceituais da ponderação, da proporcionalidade, da orientação às consequências, dos princípios de moralidade política, etc. Mas no fundo, os referentes utilizados na interpretação da resposta do direito para o caso são plurais, são diferentes: em vez de um mundo do direito, sob o paradigma da Différence, temos agora uma "pluralidade de mundos" (GABRIEL, 2015, p. 134).

\section{A hermenêutica da Différence}

Entendemos por paradigma da Différence o conjunto de práticas que pressupõem um sistema de formação exógena do sentido (CEVOLO, 2016b, p. 574). Um sistema ontológico que não admite a existência de uma realidade independente de uma correlação entre mundo e referente (MEILLASSOUX, 2006, p. 18, 2014, p. 9). E exatamente por não admitir a existência de um ser independente do seu correlato - consciente, noemático, linguístico ou discursivo -, o paradigma da Différence pressupõe que o real não pode ser um referente, pois apenas a correlação pode ser real, apenas a diferença pode sê-lo.

Nos sistemas de formação endógena do sentido, como são exemplos os sistemas filosóficos do mundo pré-crítico (antes de Kant), o sentido é construído de modo convergente e coerente, buscando-se o reconhecimento, a reconciliação dos elementos e a unidade. Desse modo, o sentir, o pensar e o agir são colocados em operação por um sistema de pensamento que converge em uma identidade complexa e coerente (CEVOLO, 2016b, p. 570).

Por outro lado, nos sistemas de formação exógena do sentido, a construção parte de uma noção de exterior, parte de um externalismo semântico: o signo e sua relação entre significado e 
significante são definidos por referentes exteriores a ele, como as relações de poder, os modelos de comunicação, as lógicas sociais, as estruturas sociais, os paradigmas de percepção, as tradições da cultura, etc. Na formação exógena, o signo é entendido como uma referência vazia, puramente formal, a qual é preenchida por relações externas. O sentido, nessa perspectiva exógena de formação de sentido, é construído de modo divergente e incoerente, buscando-se não o reconhecimento, a reconciliação e a unidade, mas a dispersão, a assimetria e a plurirreferencialidade. Esse sistema desassocia o conceito de sentido do conceito de identidade. E, desse modo, o sentir, o pensar e o agir são colocados em operação por um sistema de pensamento que diverge em uma identidade incoerente (CEVOLO, 2016b, p. 573).

Modelos ecumênicos na religião, modelos colaborativos na administração, modelos desrrelativos na sexualidade, modelos dialógico-interpretativos no campo das éticas, modelos multidimensionais no campo da pedagogia, modelos pluralistas no campo do direito e da política. Não é coincidência esse triunfo do paradigma da Différence em todas essas áreas da experiência social. E também não é coincidência o fato de qualquer tentativa no sentido de se questionar ou desconstruir a prática ecumênica na religião, o colaboracionismo na cultura empresarial, a desrrelação na sexualidade, a dialogia na ética, a multidimensionalidade na pedagogia ou o pluralismo na política e no direito já ser vista, de antemão, como práticas conservadoras. O efeito de paradigma é justamente apresentar como conservadora qualquer tentativa de desconstrução crítica dos seus pressupostos, da sua operacionalidade e da sua efeitualidade.

A hermenêutica constitucional, nesse paradigma da Différence, já não procura mais a coerência e a convergência interpretativa do sentido dos conceitos e institutos jurídicos. Pelo contrário, a hermenêutica constitucional procura justamente se afastar de uma prática de convergência e de coerência, como estratégia de progresso da jurisprudência. Isso porque, no paradigma da Différence, a convergência e a coerência são entendidas como práticas conservadoras de interpretação jurídica, isto é, são entendidas como formações discursivas que não lidam bem com a diferença, com o pluralismo democrático, com a mudança e com a transformação social. Procurar a coerência e a convergência do sentido passou a ser uma prática, como podemos dizer, dogmática do direito.

intérprete do direito prestigiado por esse paradigma é aquele que sabe lidar com as diferenças, que está sintonizado com o discurso dos movimentos sociais intelectualizados e da militância política organizada e seus regimes de pós-verdade, de realidade construída discursivamente, de luta simbólica pela afirmação de direitos, etc. Os precedentes construídos sob essa forma de discurso logo conquistam espaços na mídia de massa, que também trabalha sob o paradigma da Différence, segundo o qual a informação que possui valor de mídia é justamente aquela hipérbole da realidade, o exagero, a dramatização, a polêmica surpreendente, impactante, "diferente" da tradição jurisprudencial até então firmada e que, por isso, gera mais polêmica, dissenso, dispersão, assimetria e incoerência - e não mais a informação da coerência, da identidade e da unidade do direito. 
O paradigma da Différence valoriza o dissenso e não o consenso, a dispersão da polêmica e não a reconciliação da sabedoria, a assimetria e não a unidade, a incoerência e não a coerência, a divergência e não a convergência. A genealogia da interpretação, dizia Foucault (1971, p. 158), faz aparecer as diferentes interpretações "como acontecimentos no teatro dos procedimentos." O pensamento da Différence é o pensamento da desconstrução, da renúncia às essências, aos télos, ao sujeito, às identidades e às coerências. Uma espécie de "filosofia do terror" (ROSSET, 1989, p. 58): do pensamento trágico em busca de aprovação.

O efeito de paradigma é deslocar os regimes de verdade para outras configurações de sentido, nem melhores, tampouco piores, mas sempre diferentes. Por isso, o triunfo do pensamento da Différence também apresenta problemas. Se o signo do direito é vazio e sua determinação depende de um externalismo semântico radical, então o direito pode ser qualquer coisa, quer dizer, o direito pode ser qualquer coisa que a elite jurídica de cada época, que possui a competência normativa ou a posição institucional adequada, decidir que ele deva ser.

\section{A reconstrução do problema da hermenêutica constitucional e o novo realismo especulativo}

O novo problema da hermenêutica constitucional está em pensar na definição de um referente semântico para o direito que renove o compromisso da interpretação jurídica com uma realidade coerente do mundo. Porque na prática jurídica brasileira, especialmente a dos tribunais superiores, nas quais os holofotes da mídia e os jogos de sedução da política são mais evidentes, a referência do direito não é mais aquilo que conhecíamos como as fontes do direito. Nem mesmo a constituição e seus princípios fundamentais desempenham, hoje, a efeitualidade de um horizonte interpretativo relevante para os discursos jurídicos dos tribunais superiores. No paradigma da Différence o que vale é a surpresa, a divergência, a polêmica, a identidade incoerente, enfim, a diferença.

Quando o direito deixa de possuir uma base de realidade sobre a qual não se pode divergir, a interpretação constitucional passa a poder utilizar qualquer referente externo como base para "fechar" seus argumentos. O externalismo semântico se torna radical quando, por razões de ordem política, econômica, religiosa, etc., os próprios direitos fundamentais passam a sofrer limitações. Para os ricos, liberdade, igualdade e dignidade incondicionais. Para os pobres, reserva do possível (mesmo diante de cláusulas pétreas). Para os ricos, ato jurídico perfeito, segurança jurídica e irretroatividade. Para os pobres, reforma trabalhista e previdenciária. Para os ricos, ponderação entre intimidade e liberdade de expressão. Para os pobres, ponderação entre saúde, educação e vagas no SUS ou na escola.

Não afirmamos que devemos renunciar ao externalismo semântico do paradigma da Différence para voltar à metafísica pré-crítica do pensamento dogmático. Queremos, na verdade, observar os novos desafios que esse paradigma apresenta para a hermenêutica constitucional, especialmente em países periféricos e com altos índices de desigualdade social como o Brasil. Queremos, sobretudo, 
colocar em discussão a importância da construção de um novo referente à interpretação constitucional, capaz de reestabelecer os compromissos interpretativos com a coerência e com a unidade convergente do direito. Uma nova hipoteticidade absoluta (MEILLASSOUX, 2011, p. 101) a respeito do referente jurídico.

Princípios de moralidade política (Dworkin), tópica (Viehweg), razoabilidade (MacCormick), ponderação (Alexy), consenso sob condições ideais (Habermas), interpretação conforme à Constituição (Streck), mediação dialética entre sistema jurídico e problema do mundo prático (Castanheira Neves), criação de um novo sistema de sentido (Luhmann), mediações estruturadas por acoplamentos estruturais (Teubner), dentre tantas outras, são propostas de referentes possíveis para a interpretação jurídica construir o sentido do direito. A ocupação desses espaços de produção de sentido do direito, entretanto, depende de relações de poder que, atualmente, parecem ser comandadas pelos tribunais superiores, em especial pelo STF.

Cabe à academia, advocacias pública e privada e demais instituições jurídicas questionar a legitimidade da ocupação desses espaços de poder da "fala autorizada" do direito. Porque embora o paradigma da Différence afirme que a realidade é uma construção discursiva e que, por isso, ela pode ser qualquer coisa dependendo de quem está no poder, de quem possui o poder de institucionalizar um regime e não outro de verdade, não podemos aceitar que, na ausência de uma realidade jurídica coerente, essa realidade possa ser definida exclusivamente pelas convicções e estratégias políticas dos tribunais superiores. $O$ direito em países de modernidade periférica como o Brasil é um sistema simbólico muito importante da comunidade política para se entregá-lo à apropriação privada e exclusiva de uma elite jurídica localizada nos tribunais superiores e em suas vizinhanças.

Dworkin para os ricos, Alexy para os pobres. Para os ricos: "levando os direitos à sério", "o império do direito" (DWORKIN, 1978, 1986). Para os pobres: colisão, restrição de direitos, ponderação, proporcionalidade e reserva do possível (ALEXY, 2002). O pluralismo da Différence é um sistema de sentido que, como todos os outros que o antecederam, também possui seu lado de arbítrio, de violência, de paradoxo e, portanto, também de fideísmo: a crença na correlação como o novo absoluto em um pensamento cujo sentido estava exatamente na desconstrução do absoluto (MEILLASSOUX, 2006, p. 20).

\section{Considerações finais: rumo a uma hermenêutica constitucional plural?}

Nessa perspectiva, o problema do decisionismo judicial, que a hermenêutica constitucional visa combater, pode ser entendido não apenas como um problema de indeterminação da linguagem "aberta" dos princípios constitucionais ou como um problema de interpretação subjetivista do juiz, mas também como: um problema de apropriação privada e exclusiva da episteme do direito, isto é, de ocupação exclusiva dos espaços de produção de sentido do direito, de apropriação do direito de dizer o que é e o que pode vir a ser direito; um problema que está inscrito nos desenhos institucio- 
nais do judiciário, da advocacia pública e privada e da academia jurídica, isto é, não necessariamente um problema de subjetividade do juiz, do advogado ou do professor de direito, mas uma questão de estrutura, de organização, uma questão na relação de poder entre as instituições jurídicas; e um problema de plurirreferencialidade do direito, já que não estamos nem no positivismo jurídico, tampouco assumimos um compromisso com algum referente recomendado por uma teoria contemporânea da interpretação em particular. Estamos, na verdade, vivendo o pluralismo de teorias interpretativas do direito e seus diferentes referentes.

No campo do direito, o paradigma da Différence produziu o triunfo do pluralismo. Uma olhada mais cuidadosa nos discursos acadêmicos permite observar como o pluralismo e suas diversas formas de expressão (transconstitucionalismo, constitucionalismo societário, democracia em redes, soft law, soberania, globalização, multiculturalismo e todos os trans, inter, multi, eco, etc.) têm sido a referência-chave para fechar a argumentação que, há pouco tempo, contentava-se com mais dignidade, mais igualdade ou mais liberdade. O pluralismo da Différence triunfou também no campo da ciência, que hoje valoriza muito mais a transdisciplinariedade do que a especialidade, a complexidade do que a simplicidade, o pluralismo de saberes do que o domínio de habilidades e competências técnicas especializadas. No nível dos discursos acadêmicos, também as pesquisas científicas têm indicado soluções pluralistas para os problemas teóricos do direito, do Estado e da democracia. Inclusive no campo da hermenêutica jurídica se fala em "hermenêutica plural".

Retornando à Kelsen, que foi nosso ponto de partida para este final de percurso desconstrucionista - que também é típico de um pensamento da Différence -, o problema da hermenêutica constitucional é que, se Kurt Gödel tinha razão, qualquer tentativa de construção de um novo referente, isto é, qualquer tentativa de se buscar a completude em um novo sistema simbólico, para suplementar a inconsistência do referente atual, sempre vai se deparar com um novo nível de incompletude, de inconsistência. Ao buscarem-se experiências de pluralismo jurídico para suplementar a ausência de completude no horizonte interpretativo dos direitos fundamentais sociais estaremos resolvendo o problema do decisionismo no nível da interpretação dos direitos fundamentais, mas estaremos, paradoxalmente, criando um sempre novo e penúltimo problema: a incompletude no novo modelo pluralista de compreensão dos direitos fundamentais sociais.

\section{Referências}

ALEXY, Robert. Teoría de los derechos fundamentales. Tradução Ernesto Garzón Valdés. Madrid: Centro de Estudios Constitucionales, 2002.

ASSIS, Ana Elisa Spaolonzi Queiroz. Direito à educação e diálogo entre poderes. 2012. 259 p. Tese (Doutorado em Educação)-Faculdade de Educação, Unicamp, São Paulo, 2012.

BADIOU, Alain. The Democratic Emblem. In: AGAMBEN, Giorgio et al. Democracy in what State? Tradução William McCuaig. New York: Columbia University Press, 2010. 
CEVOLO, Vicente Augusto Gabriel Leite. As sombras vazias. Revista da Faculdade de Direito do Sul de Minas, v. 32, n. 1, p. 405-416, jan./jun. 2016.

CEVOLO, Vicente Augusto Gabriel Leite. Do corpo subculturado ao sujeito de cultura. In: SILVA, José Vitor da; BRAGA, Cristiane Giffoni. Cuidados Paliativos na Perspectiva Contemporânea. Curitiba: Prismas, 2016.

DELEUZE, Gilles. Logique du sens. Paris: Les Éditions de Minuit, 1969.

DERRIDA, Jacques. Marges de la phisolophie. Paris: Les Éditions de Minuit, 1972.

DWORKIN, Ronald. Law's empire. Cambridge: Harvard University Press, 1986.

DWORKIN, Ronald. Taking rights seriously. Cambridge: Harvard University Press, 1978.

FOUCAULT, Michel. L'Archéologie du savoir. Paris: Gallimard, 1969.

FOUCAULT, Michel. Nietzsche, la généalogie, l'histoire. In: BACHELARD, Suzane et al. Hommage à Jean Hyppolite. Paris: Presses Universitaires de France, 1971. p. 145-172.

GABRIEL, Markus. Why the World Does Not Exist. Tradução Gregory S. Moss. Cambridge: Malden: Polity Press, 2015.

GÖDEL, Kurt. On formally undecidable propositions of Principia Mathematica and related systems. Tradução B. Meltzer. New York: Dover Publications Inc., 1992.

HABERLE, Peter. Hermenêutica Constitucional. A sociedade aberta dos intérpretes da Constituição: contribuição para a interpretação pluralista e 'procedimental' da Constituição. Tradução Gilmar Ferreira Mendes. Porto Alegre: Safe, 1997.

KELSEN, Hans. Teoria geral das normas. Tradução José Florentino Duarte. Porto Alegre: Safe, 1986.

KELSEN, Hans. Teoria geral do direito e do Estado. Tradução Luís Carlos Borges. São Paulo: Martins Fontes, 2000.

KELSEN, Hans. Teoria pura do direito. Tradução João Baptista Machado. São Paulo: Martins Fontes, 1985.

LUHMANN, Niklas. Das Recht der Gesellschaft. Frankfurt am Main: Suhrkamp, 1995.

MEILLASSOUX, Quentin. Après la finitude: essai sur la necessite de la contingence. Paris: Éditions du Seuil, 2006.

MEILlASSOUX, Quentin. Le Nombre et la sirene: un déchiffrage du Coup de dés de Mallarmé. Paris: Librairie Arhème Fayard, 2011.

MEILLASSOUX, Quentin. Time without becoming. Mimesis Int1., 2014.

NAGEL, Ernest; NEWMAN, James R. A prova de Gödel. Tradução Gita K. Guinsburg. São Paulo: Perspectiva, 2003. 
RODRIGUEZ, José Rodrigo. Como decidem as Cortes? Para uma crítica do direito (brasileiro). Disponível em: <https://www.uniceub.br/media/364804/comodecidemascortes.pdf>. Acesso em: 10 jul. 2017.

ROSSET, Clément. Lógica do pior. Tradução Fernando J. Fagundes Ribeiro e Ivana Bentes. Rio de Janeiro: Espaço e Tempo, 1989.

SANTOS, Boaventura de Sousa. A crítica da razão indolente: contra o desperdício da experiência. São Paulo: Cortez, 2002.

SAUSSURE, Ferdinand. Curso de linguística geral. Tradução Antônio Chelini, José Paulo Paes e Izidoro Blikstein. São Paulo: Cultrix, 2006.

STRECK, Lenio Luiz. Hermenêutica jurídica e $(m)$ crise: uma exploração hermenêutica da construção do direito. 3. ed. Porto Alegre: Livraria do Advogado, 2001.

STRECK, Lenio Luiz. Jurisdição Constitucional e Hermenêutica: uma nova crítica do direito. Porto Alegre: Livraria do Advogado, 2002.

STRECK, Lenio Luiz. Verdade e consenso: Constituição, Hermenêutica e Teorias Discursivas. Rio de Janeiro: Lúmen Júris, 2006.

WARAT, Luis Alberto; ROCHA, Leonel Severo. O direito e sua linguagem. 2. versão. Porto Alegre: Safe, 1995.

Data da submissão: 26 de julho de 2017 Avaliado em: 13 de novembro de 2017 (AVALIADOR C) Avaliado em: 24 de novembro de 2017 (AVALIADOR D) Aceito em: 09 de abril de 2018 